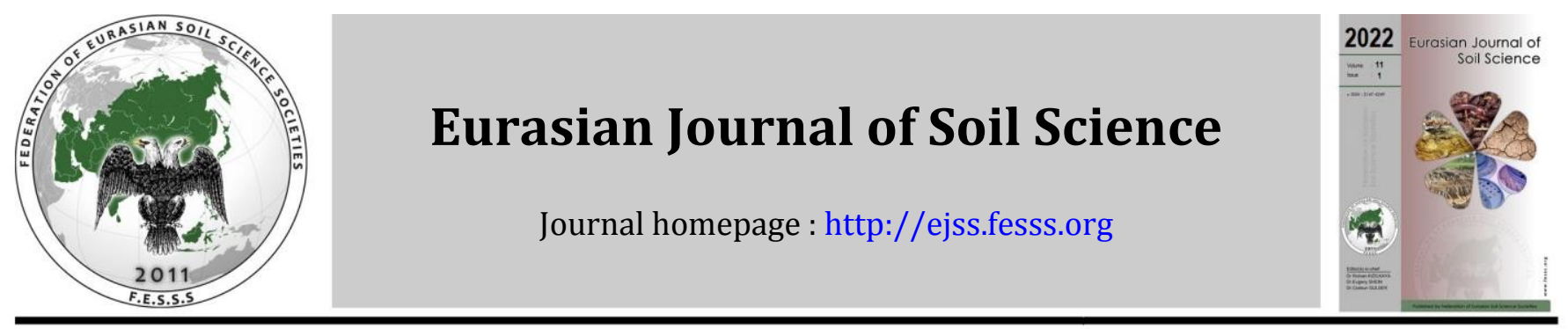

\title{
Identification of humic substances on the transformation of an organic substrate
}

\author{
Olga Bezuglova a,*, Andrey Komarov b, Alexey Komarov c \\ a Southern Federal University, Academy of Biology and Biotechnology, 344090, Rostov-on-Don, Russia \\ b Agrophysical Research Institute, pr. Grazhdanskiy 14, 195220, St. Petersburg, Russia \\ c Leningrad Research Institute of Agriculture "Belogorka", Institutskaya street, Leningrad region, Gatchinsky district, \\ Belogorka village, 188338 Russia
}

\section{Article Info}

Received : 08.02.2021

Accepted : 20.07.2021

Available online : 25.07.2021

\section{Author(s) \\ O. Bezuglova * \\ A. Komarov \\ A. Komarov}

* Corresponding author

\begin{abstract}
The organic matter of the soil and humus are heterogeneous in composition. That is why the nature of soil organic matter has not yet been fully understood and causes many discussions. The purpose of this work is to study the identification features of humus in the process of peat's transformation. The results of a fiveyear experiment studying the processes of organic matter transformation in organic-mineral substrate based on peat growing coniferous seedlings in greenhouses are presented. In the dynamics of the group and fractional composition of humus for several years the biochemical essence of the humification process is revealed. To extract specific humic substances from the organogenic substrate, we used the method of fractioning humus into groups and fractions, which is a stepwise sequential extraction using solutions of sodium hydroxide and sulfuric acid. It was found that the organic matter of the substrate passes through three stages of transformation: hydrolysis of organic products $\rightarrow$ initial transformation $\rightarrow$ humification of lignin structures. There is a significant change in the ratio of the three main groups of humus in favor of humic acids at the third stage. In general, the system is tends to its most stable state: aromatic structures are copolymerized, the core of humic substances is densified, and humus gradually "matures".
\end{abstract}

Keywords: Fulvic acid, humic acid, humus formation, peat.

(c) 2022 Federation of Eurasian Soil Science Societies. All rights reserved

\section{Introduction}

The organic matter of the soil and humus are heterogeneous in composition. That is predetermined by their chemical properties, the degree of organic residues transformation, the nature of their transformations, and also due to the connection of humic compounds with each other and with the mineral part of the soil. Humic acids (HA) are known to be the most specific part of humus. The amphiphilic nature of humic acids determines the formation of micelle-like structures. This property of HAs in neutral and acidic conditions determines the protective properties of soil organic matter, binding pollutants and preventing their entry into adjacent environments (Sannino and Piccolo, 2013). The composition of soil organic matter and its properties cause intense interest of scientists (Sbih et al., 2012; Hristov and Filcheva, 2017; Shahin and Khater, 2020). Its study is possible from different perspectives, so various approaches were developed at different times and in different countries to solve this very difficult task.

In particular, the method of Tyurin (1951) was widely used in the USSR. This method involved the fractionation of soil organic matter into groups by the relation to solvents and into fractions by the connection of organic molecules with the mineral part of the soil. The most famous adaptation of Tyurin's method became modification of Ponomareva and Plotnikova (1980). 
The principles underlying the method have been very productive, proof of which is the establishment with its help of the geographical patterns of humus formation. Studies (Orlov et al., 2004) have shown, that the degree and depth of organic matter humification in the upper humus horizon, established according to the number and ratio of the main humus groups in its composition, closely correlated with the duration of the period of biological activity (PBA). Modern studies using this method show that variations in the humus composition, ceteris paribus, can be caused not only by zonal differences in climate, but also by the relief features (Dubovik and Cherkasov, 2013). Even such a factor as location on slopes of different exposure affects the composition of humus. The authors showed that "humid climate of northern slopes leads to formation of brown type of humic acids (HA), while the conditions of eastern slopes assist to formation of gray HA". Moreover, for example: "Cambisols are characterized by dominance of fulvic acids (FA) above HA" regardless of the location: whether it is Jiguli Ridges in Samara Region of Russia (Abakumov et al., 2009) or Caucasus mountains of the Republic of Armenia (Kroyan, 2018).

The presence of such regularities disproves the postulate that humic substances are just a complex mixture of identifiable biopolymers (Lehmann et al., 2008; Lehmann and Kleber, 2015). The specificity of humic substances acts here as a sign of identification of the soil state, which an ordinary mixture of organic compounds just cannot do. More convincing is the concept that HSs have a supramolecular structure (Piccolo, 2001; 2002). According to Piccolo, this concept of HS structure gives a better insight into the key contribution of HSs to ensuring and maintaining the physical and chemical properties of soils and their reactivity to pesticides and other environmental pollutants. Later on Nebbioso and Piccolo $(2011 ; 2012)$ with the help of the fractionation and chromatography of HSs, found that hydrophobic compounds are mainly distributed in the coarsest fraction, while hydrophilic components are eluted in the finest fraction. The proportions of these molecular components determine the hydrophobicity or hydrophilicity of HSs. This hypothesis is consistent with the hydrophobic properties of HA nucleus and the hydrophilicity of peripheral chains (Orlov, 1992). In fact, humus compounds are a humus matrix of complex multilevel organization (Fedotov and Dobrovolskiy, 2012). It was also found that the supramolecular organization of HAs in Chernozems and Kastanozems can be described as a spatial structure composed of 2-4 layers of condensed aromatic systems supplemented by a network of chain fragments with different degrees of regularity and lengths (Bezuglova, 2019). The purpose of this work is to study the identification features of humus in the process of long-term transformation through successive stages of the extraction of specific humic substances from a typical organogenic substrate (greenhouse soils) using alkaline and acid reagents.

\section{Material and Methods}

\section{Materials}

The object of research was an organic-mineral substrate based on peat, which is used in the system of the protected ground when growing plants in greenhouses. The main part of its composition is the peat mined by milling process. It has a favorable air-water regime for plants, and it is a good antiseptic. Peat was preliminarily neutralized by lime until a neutral medium reaction and was saturated with nutrients by adding mineral fertilizers according to the technology of preparing greenhouse soils (Lapin and Nollendorf, 1975). The transformation of the substrate used for growing coniferous seedlings is considered in this work. The initial characteristics of the substrate and its biochemical and agrochemical parameters were performed in accordance with State Standard 27753.0-88 (Greenhouse soils. General requirements for methods of analysis), are presented in Table 1.

Table 1 The five-year dynamics of organomineral substrates' agrochemical indicators in greenhouse conditions

\begin{tabular}{|c|c|c|c|c|}
\hline \multirow{2}{*}{$\begin{array}{l}\text { Agrochemical } \\
\text { indicators }\end{array}$} & \multicolumn{4}{|c|}{ The term of the substrate use, years } \\
\hline & Initial & 1 & 3 & 5 \\
\hline Ash content, $\%$ & $2,2 \pm 0,2$ & $5,8 \pm 0,6$ & $10,2 \pm 0,7$ & $41,7 \pm 0,7$ \\
\hline $\mathrm{C}, \%$ & $44,2 \pm 0,7$ & $36,7 \pm 0,5$ & $29,6 \pm 0,3$ & $19,5 \pm 0,3$ \\
\hline $\mathrm{N}, \%$ & 1,01 & 0,95 & 0,93 & 0,90 \\
\hline $\mathrm{P}_{2} \mathrm{O}_{5}, \%$ & 0,07 & 0,16 & 0,17 & 0,18 \\
\hline $\mathrm{C} / \mathrm{N}$ & 41,70 & 38,60 & 31,8 & 21,70 \\
\hline $\mathrm{N}-\mathrm{NH}_{4}, \mathrm{mM}(+) / 100 \mathrm{~g}$ & $17,5 \pm 5,2$ & $12,5 \pm 2,3$ & $8,7 \pm 1,7$ & $11,8 \pm 2,7$ \\
\hline $\mathrm{N}-\mathrm{NO}_{3}, \mathrm{mM}(+) / 100 \mathrm{~g}$ & 2,80 & 5,20 & 3,10 & 5,30 \\
\hline $\mathrm{N}$ mineral, $\mathrm{mM}(+) / 100 \mathrm{~g}$ & 20,30 & 17,70 & 11,80 & 17,10 \\
\hline $\mathrm{P}_{2} \mathrm{O}_{5}, \mathrm{mM}(+) / 100 \mathrm{~g}$ & 16,20 & 16,20 & 24,90 & 61,70 \\
\hline $\mathrm{K}_{2} \mathrm{O}, \mathrm{mM}(+) / 100 \mathrm{~g}$ & 29,00 & 298,00 & 111,00 & 30,00 \\
\hline The total amount of exchangeable bases, $\mathrm{mM}(+) / 100 \mathrm{~g}$ & 1,12 & 6,12 & 6,00 & 6,80 \\
\hline Hydrolytic acidity, $\mathrm{mM}(+) / 100 \mathrm{~g}$ & 9,33 & 4,26 & 3,91 & 2,34 \\
\hline Base saturation, $\%$ & 10,70 & 58,90 & 60,50 & 74,40 \\
\hline
\end{tabular}

\pm- the standard deviation (SD) 


\section{Fractionation of humic substances}

To extract specific humic substances from the organogenic substrate, the method of fractionation of the group and fractional composition of humus was proposed by Tyurin and modified by Ponomareva and Plotnikova (1980). This method is a step-sequential extraction using dilute solutions of sodium hydroxide and sulfuric acid. The analysis scheme of the humus composition according to Ponomareva and Plotnikova (1980) provides for the determination of three groups of humus: humic acids (HA), fulvic acids (FA) and humins (Hm) - non-hydrolyzable residue. Humic acids are extracted from the soil with $0.1 \mathrm{~N}$ sodium hydroxide solution. The combination of soil treatment with an alkaline solution with other operations allows us to subdivide humic acids into three fractions according to their relationship with the mineral part of the soil. Free and associated with mobile sesquioxides humic compounds (HA-1) are extracted directly from the soil in its natural state. Humic acids associated with exchange calcium and magnesium (HA-2) are extracted with an alkaline solution from decalcified soil, previously destroying salts of divalent cations by treating the soil with a $0.1 \mathrm{~N}$ sulfuric acid solution. Humic acids associated with stable forms of iron and aluminum oxides and clay minerals (HA-3) are extracted from soil already devoid of calcium and magnesium humates using a $0.02 \mathrm{~N}$ solution of $\mathrm{NaOH}$, after being subjected to 6-hour alkaline hydrolysis in aqueous bath.Fulvic acids, in turn, are divided into 4 fractions. One fraction, represented by free fulvic acids (FA-1a), is extracted from the soil using $0.1 \mathrm{~N}$ solution of $\mathrm{H}_{2} \mathrm{SO}_{4}$. Three fractions of fulvic acids, which are in polymer bonds with the humic acids of the corresponding fractions and the mineral components of these fractions, are extracted together with humic acids and then the HA is separated by its precipitating from an alkaline solution using sulfuric acid. Fulvic acids remain in solution. The non-hydrolyzable residue (humine) is found by the difference between the total content of organic carbon in the soil and the sum of the organic carbon of all fractions. It characterizes the strength of fixing humic substances by the mineral part of the soil. However, compounds having a weak degree of humification of organic matter, such as those that are in peat, forest litter, etc., also get in this fraction. The processing of the experimental results was carried out in accordance with the method of field experiment (Dospekhov, 1985) and with the help of Statgraphics Plus software for Windows (Matveeva and Valeeva, 2012).

\section{Results}

\section{Change in soil-agrochemical indicators of soil}

The dynamics of changes of the main agrochemical and biochemical parameters in the process of using the substrate are presented in Table 1 . The content of basic nutrients in the process of using the substrate changed slightly and was at the optimum level to provide the cultivated plants.

The total amount of exchangeable bases increased from 6.12 (in the first year) to $6.80 \mathrm{mM}(+) / 100 \mathrm{~g}$. (by the fifth year). The degree of saturation with bases also increased (from 58.9 to $\mathrm{mM}(+) / 100$ g.), in parallel, hydrolytic acidity significantly decreased - from 4.26 to $2.34 \mathrm{mM}(+) / 100 \mathrm{~g}$. All this indicates significant improvement in soil quality by agrochemical indicators and characterizes the intensive transformation of organic matter from an organic substrate into organic-mineral soil.

This demonstrates that the transformation of the substrate in the system of estimated indicators over a period of 5 years has a continuous progressive character. Thus, two processes are observed: the process of mineralization of organic matter, which is accompanied by an increase in ash content from $2.2 \%$ to $41.7 \%$ (Figure 1), and a decrease in the total carbon content from $44.2 \%$ to $19.5 \%$ (Figure 2 (C, \%)). The change in the ratio of carbon to nitrogen by the fifth year of the experiment is fixed at $\mathrm{C} / \mathrm{N}=21.7$. This indicates directed optimization of the balance between carbon and nitrogen (Figure $2(\mathrm{~N}, \%)$ ), which is not so much characteristic of a mixture of mineralized substrate as a self-regulating system, which is characteristic of highly productive soils. Thus, the transformation of the substrate is aimed at changing the ratio of the mineral and organic parts to the level of ratios close to the natural soil.

It is known (Gmurman, 2004) that the correlation coefficient (r) serves as a mathematical measure of the relationship between two random variables. Evaluating the statistically significant $(\mathrm{P}=95 \%)$ relationship between the main indicators that determine the transformation of the substrate (Ash content, total C, total $\mathrm{N}$, one can observe a fairly strong relationship between the estimated indicators. For Ash content - total C and for Ash content - total $\mathrm{N}$, there is a strong negative correlation ( $\mathrm{r}=-0.91$ and $\mathrm{r}=-0.80$, respectively). At the same time, a very strong positive correlation is observed between total $\mathrm{C}$ and total $\mathrm{N}$ content $(\mathrm{r}=0.96)$.

Summing up the analysis of the quality of the substrate according to the main agrochemical indicators, it can be noted that the nutritional qualities of the substrate during its use did not deteriorate but improved. 


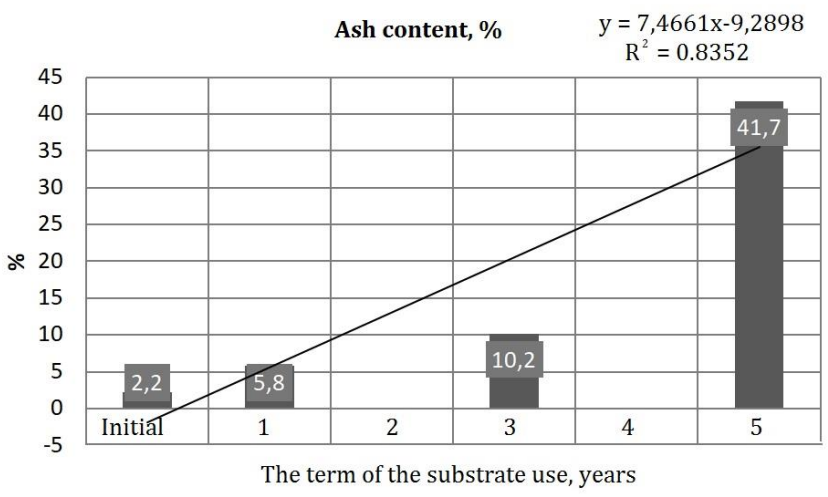

Figure 1. Dynamics of ash content over time, \%
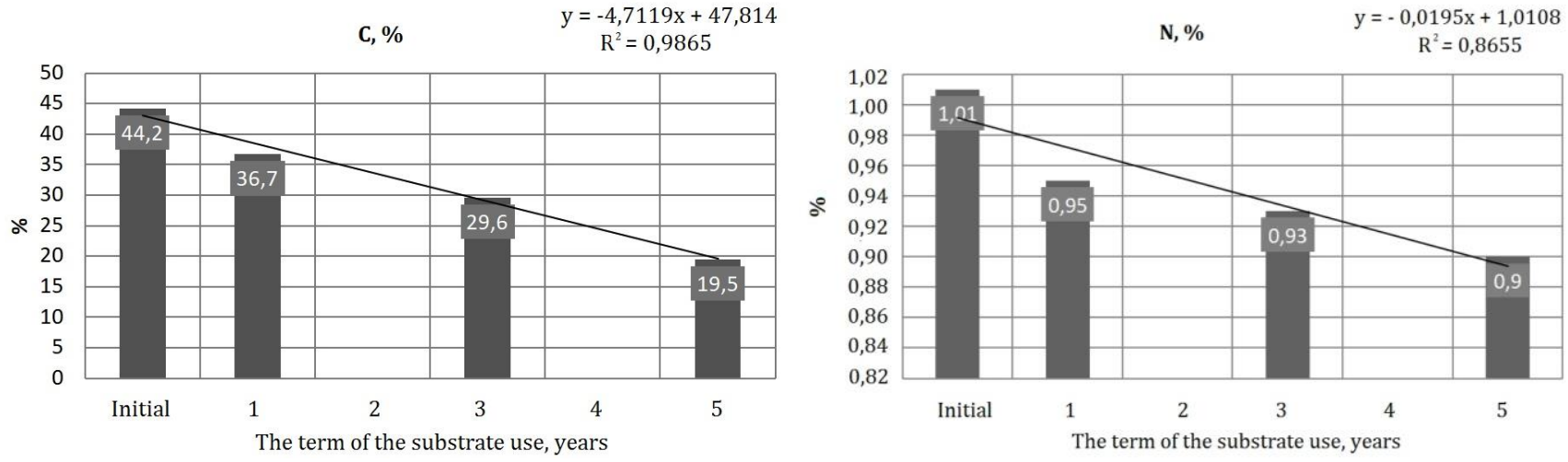

Figure 2. Dynamics of total carbon (C, \%) and total nitrogen (N, \%) content over time,\%

\section{Change in the quality state of humic substances}

Agrochemical indicators cannot serve as a universal criterion for assessing the suitability of a substrate for plants growing. The criterion for assessing the suitability of peat grounds for their use in the form of a nutrient substrate in the conditions of protected ground can be an assessment of the specifics of the formation of humic substances that regulate plant growth and development. For this purpose, the dynamics of the group and fractional composition of humic substances formed during the transformation of organicmineral substrate for several years was evaluated. We were interested in this criterion as evidence of the specificity of humus formation, during which a special class of organic substances that can fulfill the communication-regulatory role in the functioning of plants is gradually formed.

Table 2 presents the data on changes in the group and fractional composition of the humic substances of the organic-mineral substrate in the process of its use. They indicate a significant increase of all fractions of humic acids, especially the first fraction (brown HA), with an increase in the period of the substrate use. Statistical processing of the experimental results has shown, that the dynamics of various fractions of humic substances changes in the substrate can be described by a simple linear function. A high level of reliable approximation is noted for the total accumulation of humic acids $\left(\mathrm{R}^{2}=0.76\right)$ and especially the HA- 2 fraction $\left(\mathrm{R}^{2}=0.94\right)$. Somewhat lower $\left(\mathrm{R}^{2}=0.60-0.61\right)$ was the approximation for HA-1 and HA-3 fractions. For the fractions of fulvic acids, an increasing linear function was noted for the FA-1a $\left(\mathrm{R}^{2}=0.74\right)$ and FA-1 $\left(\mathrm{R}^{2}=\right.$ $0.82)$ fractions. For the FA-2 $\left(\mathrm{R}^{2}=0.56\right)$ and FA-3 $\left(\mathrm{R}^{2}=0.78\right)$ fractions, a decrease in the accumulation was noted. Thus, the total accumulation of fulvic acid fractions had an unreliable level of approximation $\left(\mathrm{R}^{2}=\right.$ $0.43)$. The most significant statistical indicators $\left(R^{2}=0.99\right)$ are noted for a decrease in the total carbon content and the proportion of non-hydrolyzable residue $\left(\mathrm{R}^{2}=0.71\right)$, which can be explained by the mineralization of the substrate.

It was revealed that in the process of transformation of the organic-mineral substrate, coupled processes of both mineralization and humification of the source material are observed. These processes involve not only labile, easily hydrolyzable components of organic matter, but also a non-hydrolyzable residue (represented mainly by lignin), as evidenced by a threefold decrease in its participation in the composition of organic matter in the fifth year of the study. This result is in good agreement with the concept of humification, that is unambiguously described as the progressive accumulation of hydrophobic molecular components (Piccolo et al,, 2019). 
Table 2. Changes in the group and fractional composition of humic substances of the substrate in the process of its use (\% of total carbon)

\begin{tabular}{|c|c|c|c|c|c|c|c|c|c|c|c|c|c|}
\hline \multirow{3}{*}{ Years } & \multirow{3}{*}{ Corg, \% } & \multicolumn{10}{|c|}{$\%$ of the soil Corg. } & \multirow{3}{*}{$\frac{\underline{C}_{\mathrm{HA}}}{\mathrm{C}_{\mathrm{FA}}}$} & \multirow{3}{*}{$\underline{\mathrm{C}_{\mathrm{HA}}}+\underbrace{}_{\mathrm{C}_{\mathrm{FAR}}}$} \\
\hline & & \multicolumn{4}{|c|}{ Humic Acids } & \multicolumn{5}{|c|}{ Fulvic Acids } & \multirow{2}{*}{$\mathrm{Hm}$} & & \\
\hline & & 1 & 2 & 3 & Total & $1 \mathrm{a}$ & 1 & 2 & 3 & Total & & & \\
\hline 0 & 44.23 & 12.65 & 0.41 & 17.57 & 30.36 & 0.41 & 8.46 & 4.18 & 15.28 & 28.33 & 41.31 & 1.07 & 1.42 \\
\hline 1 & 36.73 & 13.34 & 1.80 & 15.30 & 30.44 & 0.38 & 8.66 & 3.57 & 12.47 & 25.07 & 44.48 & 1.21 & 1.25 \\
\hline 3 & 29.60 & 17.71 & 2.16 & 15.68 & 35.55 & 0.58 & 10.84 & 4.02 & 12.64 & 28.08 & 36.37 & 1.27 & 1.75 \\
\hline 5 & 19.52 & 26.02 & 4.05 & 23.26 & 53.33 & 1.33 & 16.50 & 3.07 & 11.63 & 32.53 & 14.14 & 1.64 & 6.07 \\
\hline Formula & Y1 & Y2 & Y3 & Y4 & Y5 & Y6 & Y7 & Y8 & Y9 & Y10 & Y11 & & \\
\hline $\mathrm{R}^{2}$ & 0.99 & 0.61 & 0,94 & 0,60 & 0,76 & 0,74 & 0,82 & 0,56 & 0,78 & 0,43 & 0,71 & & \\
\hline \multicolumn{2}{|c|}{$\begin{array}{l}\text { Linear function: } \\
\text { Y6=0,296x-0,065 }\end{array}$} & \multicolumn{2}{|c|}{$\begin{array}{l}Y 1=-7,9 x+52.5 \\
Y 7=2,63 x+4,54\end{array}$} & \multicolumn{3}{|c|}{$\begin{array}{l}Y 2=3,242 x+10,32 \\
Y 8=-0,288 x+4,43\end{array}$} & \multicolumn{3}{|c|}{$\begin{array}{l}Y 3=1,128 x-0,715 \\
Y 9=-1,078 x+15,7\end{array}$} & $\begin{array}{l}0,945 x+ \\
1,561 x\end{array}$ & $\begin{array}{l}3,073 \\
24,6\end{array}$ & \multicolumn{2}{|c|}{$\begin{array}{l}Y 5=2,595 x+26,927 \\
Y 11=-8,962 x+56,48\end{array}$} \\
\hline
\end{tabular}

\section{Discussion}

The dynamics of this process are specific. Modeling the dynamics of the process, we divided it into three stages. The initial stage of the substrate's transformation - the hydrolysis of organic products. At the initial stages of the transformation of the organic substrate (in the first year of the experiment), the nonhydrolyzable residue is not yet involved or is poorly involved in the mineralization process, but it takes an active part in the humification process. Moreover, due to the intensive mineralization of hydrolyzable products, there is a relative increase in the proportion of non-hydrolyzable products in the substrate - from 41.31 to $44.48 \%$. This first stage of the oxidative-hydrolytic transformation of the organic matter of the substrate we called the "hydrolytic stage" or "hydrolysis".

Hydrolysis attenuation and increase in transformation: beginning of phase the stabilization. At subsequent stages (second and third year of substrate mineralization), non-hydrolyzable products (lignin) are gradually involved in the general transformation process. The proportion of non-hydrolyzable residue at this stage of the transformation decreases from $44.48 \%$ to $36.37 \%$. This stage, which we called "the beginning of the stabilization phase", is characterized by the attenuation of hydrolytic processes. Attenuation occurs due to a decrease in the proportion of hydrolyzable substrate products with a relative increase in transformation processes associated not only with the loss of mineralizable carbon, but with the redistribution and rearrangement of difficultly hydrolyzable and non-hydrolyzable components of the substrate.

This is confirmed by an increase in the proportion of specific humic substances formed during the transformation of the substrate as well as a change in the distribution of specific fractions of humic acids and fulvic acids. The changes in the content of humic substances in the first year (at the "hydrolysis" stage) were insignificant and associated mainly with a change in the fractional composition of less mature fulvic acids. Moreover, both their total share and the composition of various fractions decreased (except the first fraction).

At this stage of the oxidative-hydrolytic transformation of soil organic matter, a decrease in the proportion of non-hydrolyzable residue begins (by $18.2 \%$ ). This occurs due to the involvement of lignin structures in the transformation process. In this case, the proportion of humic substances increases - from 30.44 to $35.55 \%$ of the total carbon (C) or by $14 \%$ for humic acids, and from 25.07 to $28.08 \%$ of the total C or by $11 \%$ for fulvic acids. Moreover, a gradual increase in the share in all fractions of both humic and fulvic acids is noted. These data confirm once again that the process of humification is a process of oxidative-hydrolytic transformation of organic matter with a phased transformation of lignin structures into specific substances of humus (Alexandrova, 1980).

Humification of lignin structures - stage of transformation. The process of transformation of the nonhydrolyzable residue was especially intense in the subsequent stage (from the third to fifth year of the experiment). This stage, called "transformation", provided a more complete involvement of lignin structures in the humification process. Thus, the proportion of non-hydrolyzable residue decreased from 36.37 to $14.14 \%$ or by $61 \%$. The proportion of humic substances also increased significantly: for humic acids - from 35.5 to $53.33 \%$ of total C or by $33 \%$, and for fulvic acids - from 28.08 to $32.53 \%$ of total C or by $14 \%$.

The characteristic pattern of redistribution of the share of humic substances in fractions is also traced. Their relative increase was observed in all fractions of humic acids. For fulvic acid fractions, a relative increase was recorded only in $1 \mathrm{~A}$ and 1 st fractions, while a relative decrease was observed for the $2^{\text {nd }}$ and $3^{\text {rd }}$ fractions. This once again indicates the nature of the smooth and gradual transition of the stages of organic matter transformation into specific humic compounds, characterizing the "maturation" of humus. 
It is known that the degree of humification is estimated as the proportion of humified material (humic acids) in the composition of organic matter. The calculation of the degree of humification, using the Orlov (1992) formula (1), reveals that humification reaches a high degree during the transformation of the substrate.

$$
\mathrm{H}=[(\mathrm{CHA}: \mathrm{SOM}) \times 100]
$$

The relative change in indicators increases almost 4 times from the initial substrate, where it is 68.6, to the substrate after five years of transformation, where this indicator is already 273.2. According to Orlov (1992), this important indicator shows how fully organic residues are converted into humic substances.

The relative change in the ratio of CHA to CFA during the transformation of the substrate (Table 2) indicates an increase of humic structures in the humus composition. So, if in the initial substrate the CHA:CFA was 1.07, indicating almost equal participation of humic and fulvic acids, finally, by the fifth year, it increased to 1.64, clearly fixing the predominance of humic acids in the composition of humus. It should be noted that different authors proposed different gradations for typing humus according to this ratio (Table 3). The difference in the qualitative composition of organic matter at different stages of transformation is seen especially well if the assessment is carried out according to Alexandrova (1980).

Table 3. Classification of soil organic matter by the ratio of humus groups in its composition

\begin{tabular}{lccc}
\hline \multirow{2}{*}{ Humus type } & According to Orlov & According to Alexandrova & According to Marchik, Efremov \\
\cline { 2 - 4 } & & $\mathrm{C}_{\mathrm{HA}} / \mathrm{C}_{\mathrm{FA}}$ & $<0,5$ \\
Fulvate & $<0,5$ & $<0,6$ & $0,5-1,0$ \\
Humate-fulvate & $0,5-1,0$ & $0,6-0,8$ & $1,0-1,5$ \\
Fulvate-Humate & $1,0-2,0$ & $0,8-1,2$ & $>1,5$ \\
Humate & $>2,0$ & $>1,2$ & \\
\hline
\end{tabular}

The difference in the composition of organic matter is even clearer if the assessment according to Aliev (1978) takes into account the state of the non-hydrolyzable residue. The ratio $\left(\mathrm{C}_{\mathrm{HA}}+\mathrm{C}_{\mathrm{FA}}\right) / \mathrm{C}_{\mathrm{Hm}}$ sharply increases from 1.75 to 6.07 at the third stage when lignin structures are actively involved in the transformation processes. If we consider the significant predominance of HA over FA, we can talk about an increase in the copolymerization of aromatic structures, densification of the core of humic substances and the gradual "maturation" of humus. It is known that organo-mineral substrates of greenhouses in the process of their transformation acquire toxic properties, forcing to replace the soil after 2-3 years of their use. The effect of humic compounds as regulators of the growth and development of plants and microorganisms is widely known (de Melo et al., 2016; Bezuglova et al., 2019). The presented data by a new way reveal the hypothesis of the manifestation of the humic substances physiological activity. The structural and physiological similarity of different fragments of humic substances and natural phytohormones (Pirog et al., 2018) explains the specifics of the change in the physiological reaction of humic substances formed from the original plant residues during their transformation into humus.

At the first stage, the initial humus-forming agents get the properties of humic acids analogues in the process of carboxylation and demethoxylation. The resulting intermediate ligno-humic acids (LHA) had structural and physiological similarities with natural gibberellins. At the second stage, nitrogen was included in the structure of LHA and formed compounds were close to natural auxins. The final stage of humus formation was characterized by saturation of the aromatic matrix with nitrogen, forming structures close to natural cytokinins (Komarov and Komarov, 2017). Specific humic substances formed during the transformation of organic matter in a closed system, such as a greenhouse, can cause a toxic effect on plants due to physiologically active compounds, such as phytohormones, when the concentration rises to a critical level.

\section{Conclusion}

Studying the specifics of the formation of humic substances formed during the long-term transformation of an organogenic substrate allows us to answer the questions of what the organic matter of soils and soil-like formations is, and how specific this substance is. In the dynamics of the group and fractional composition of humus for several years, during which the stages of transformation of the organic matter of peat were successively monitored, the biochemical essence of the humification process is revealed. It was found that the substrate organic matter passes through three stages of transformation: hydrolysis of organic products $\rightarrow$ initial transformation $\rightarrow$ humification of lignin structures. At the third stage, there is a sharp change in the ratio of the three main groups of humus in favor of humic acids due to a decrease in the amount of lignin structures that made up the bulk of the non-hydrolyzable residue and were not fully humified in the previous stages. In full accordance with the thermodynamic theory of humification (Orlov, 1992), the system tends to its most stable state: aromatic structures are copolymerized, the core of humic substances is densified, and humus gradually "matures". 


\section{References}

Abakumov, E., Fujitake, N., Takashi, K., 2009. Humus and humic acids of luvisol and cambisol of jiguli ridges, Samara Region, Russia. Applied and Environmental Soil Science Article ID 671359.

Alexandrova, L.N., 1980. Soil organic matter and the processes of its transformation. Nauka Publishing House, Leningrad, Russia. 290p.

Aliev, S.A., 1978. Ecology and energy of biochemical transformation of soil organic matter. ELM Publishing House, Azerbaijan. 252p. [in Russian].

Bezuglova, 0., 2019. Molecular structure of humus acids in soils. Journal of Plant Nutrition and Soil Science 182: 676-682.

Bezuglova, O.S., Gorovtsov, A.V., Polienko, E.A. Zinchenko, V.E., Grinko, A.V., Lykhman, V.A., Dubinina, M.N., Demidov, A., 2019. Effect of humic preparation on winter wheat productivity and rhizosphere microbial community under herbicide-induced stress. Journal of Soils and Sediments 19: 2665-2675.

de Melo, G.B.A., Motta, F.L., Santana, M.H.A., 2016. Humic acids: Structural properties and multiple functionalities for novel technological developments. Materials Science and Engineering C 62: 967-974.

Dospekhov, B.A., 1985. Methods of field experiments. Agropromizdat Publishing House, Moscow, 351p. [in Russian].

Dubovik, E.V., Cherkasov, G.N., 2013. Group and fractional composition of humus of typical chernozem in the geomorphological profile on polar-facing slopes. Russian Agricultural Science 39: 156-158.

Fedotov, G.N., Dobrovolskiy, G.V., 2012. Possible ways of nanostructure development in soil gels. Eurasian Soil Science 45: 811-822.

Gmurman, V.E., 2004. Probability theory and mathematical statistics: Textbook for universities. $10^{\text {th }}$ edition, Stereotyped. Higher School. Moscow, Russia. 479p.

Hristov, B., Filcheva, E., 2017. Soil organic matter content and composition in different pedoclimatic zones of Bulgaria. Eurasian Journal of Soil Science 6(1): 65-74.

Komarov, An. A., Komarov, Al. A., 2017. The hypothesis of the manifestation of the physiological activity of humic substances in the aspect of the humification process. Agrochemical Bulletin 6: 49-54. [in Russian].

Kroyan, S.Z., 2018. The contemporary state of the humus nutrion of the cambisols of Republic of Armenia. Advances in Biotechnology and Microbiology 11(3): 555815.

Lapin, Yu. P., Nollendorf, V.F., 1975. The influence of the level of mineral nutrition on the radish crop in a peat substrate. In: Trace elements in the complex of mineral nutrition of plants. Zinatne Publishing House, Riga, Latvia, pp. 75-83.

Lehmann, J., Kleber, M., 2015. The contentious nature of soil organic matter. Nature 528: 60-68.

Lehmann, J., Solomon, D., Kinyangi, J., Dathe, L., Wirick, S., Jacobsen, C., 2008. Spatial complexity of soil organic matter forms at nanometre scales. Nature Geoscience 1: 238-242.

Marchik, T.P., Efremov, A.L., 2006. Soil science with the basics of crop production. Grodno, Belarus. 249p. [in Russian].

Matveeva, N.M., Valeeva, A.A., 2012. Statistical processing of the results of field agrochemical studies using the Statgraphics Plus for Windows package: a teaching aid for students of the Faculty of Biology and Soil Science. Kazan University, Kazan. 63p. [in Russian].

Nebbioso, A., Piccolo, A., 2011. Basis of a humeomics science: Chemical fractionation and molecular characterization of humic biosuprastructures. Biomacromolecules 12(4): 1187-1199.

Nebbioso, A., Piccolo, A., 2012. Advances in humeomics: Enhanced structural identification of humic molecules after size fractionation of a soil humic acid. Analytica Chimica Acta 720: 77-90.

Orlov, D. S., 1992. Soil Chemistry. Russian Translation, Series 92. Published by CRC Press.

Orlov, D.S, Biryukova, O.N., Rozanova, M.S., 2004. Revised system of the humus status parameters of soils and their genetic horizons. Eurasian Soil Science 37(8): 798-805.

Piccolo, A., 2001. The supramolecular structure of humic substances. Soil Science 166(11): 810-832.

Piccolo, A., 2002. The supramolecular structure of humic substances. A novel understanding of humus chemistry and implications in soil science. Advances in Agronomy 75: 57-134.

Piccolo, A., Spaccini, R., Savy, D., Drosos, M., Cozzolino, V., 2019. The Soil Humeome: Chemical Structure, Functions and Technological Perspectives. In: Sustainable Agrochemistry. Vaz Jr. S. (Ed.). Springer, Cham, pp. 183-222.

Pirog, T.P., Iutynska, G.O., Leonova, N.O., Beregova, K.A. Shevchuk, T.A., 2018. Microbial synthesis of phytohormones. Biotechnologia Acta 11(1): 1-24.

Ponomareva, V.V., Plotnikova, T.A., 1980. Humus and Soil Formation (Methods and Study Results). Nauka Publishing House, Leningrad, Russia. 222p. [in Russian].

Sannino, F., Piccolo, A., 2013. Effective remediation of contaminated soils by eco-compatible chemical, biological and biomimetic practices. In: Sustainable development in chemical engineering: innovative technologies. Basile, A., Piemonte, V., de Falco, M. (Eds.). Wiley, Chichester, UK. pp. 267-296.

Sbih, M., Karam, A., N'Dayegamiye, A., Bensid, Z., Boukaboub, A., 2012. Dynamic of the active fraction of organic matter in some meadow soils. Eurasian Journal of Soil Science 1(1): 22-27.

Shahin, R.R., Khater, H.A., 2020. Quality and quantity of soil organic matter as affected by the period of organic farming in Sekem farm, Egypt. Eurasian Journal of Soil Science 9(3): 275-281.

Tyurin, I.V., 1951. On the analysis technique for a comparative study of the composition of soil humus or humus. Transactions of the Soil Institute named after V.V. Dokuchaev 38: 23-32. [in Russian]. 